\title{
Green tobacco sickness in Poland
}

\author{
Leszek Satora', Halina Goszcz², Ewa Gomółka³, Witold Biedroń \\ 1 Poison Information Center, Jagiellonian University Medical College, Kraków, Poland \\ 2 Department of Clinical Toxicology and Environmental Diseases, the Ludwik Rydygier Specialistic Hospital, Kraków, Poland \\ 3 Department of Clinical Toxicology and Therapeutic Drug Monitoring, Jagiellonian University Medical College, Kraków, Poland
}

\section{KEY WORDS}

green tobacco sickness, Poland
Correspondence to:

Leszek Satora, MD, PhD, Ośrodek Informacji Toksykologicznej,

Uniwersytet Jagielloński, Collegium Medicum, Os. Ztotej Jesieni 1 , 31-826 Kraków, Poland,

phone: + 48-12-64-68-706, fax: + 48-12-64-68-905

e-mail: satora@wp.pl

Received: June 7, 2008

Revision accepted: July 15, 2008.

Conflict of interest: none declared. Pol Arch Med Wewn. 2009;

119 (3): 184-186

Translated by Elzibieta Cybulska, MD

Copyright by Medycyna Praktyczna, Kraków 2009

\section{ABSTRACT}

Green tobacco sickness (GTS) is an illness associated with exposure to nicotine originating directly from the growing tobacco plant. The exposure takes place in the course of activities during tobacco farming. Nausea, vomiting, headache and dizziness are the symptoms typical of GTS. The GTS cases have been most commonly reported in the USA, Japan, India and Italy. The first case of GTS in Poland has been diagnosed in a young man working on a Virginia bright tobacco plantation. The patient had symptoms typical of GTS. The toxicological analysis of urine demonstrated the presence of cotinine at the level of $869 \mathrm{ng} / \mathrm{ml}$. Intravenous fluids, anticholinergic agents and potassium supplementation were used in the treatment. Interestingly, diplopia at the initial stage of tobacco poisoning and horizontal nystagmus, which resolved on the 2 nd day of hospital stay were observed. We believe that cases of GTS occur in Poland; however patients do not seek medical care. Given that the majority of activities during tobacco farming in Poland are performed manually, it seems necessary to launch a public awareness campaign on GTS and decontamination methods.

INTRODUCTION Nicotiana tabacum L. is grown in over 100 countries. The largest plantations are located in China, Brazil, India, the USA and Malawi. These countries together account for $2 / 3$ of worldwide tobacco production. ${ }^{1}$ Tobacco farming is associated with the hazard of the so-called green tobacco sickness (GTS). The disease is caused by nicotine which penetrates through the skin of the hands of workers who cultivate and harvest tobacco. ${ }^{1-4}$ The absorption of nicotine increases with the presence of epidermal lesions and air humidity. The symptoms of GTS might resemble those of the pesticide exposure, the initial phase of heat stroke, or poisoning in novice smokers, and may thus be confused with them. The GTS morbidity concerns nearly $1 / 4$ of tobacco workers. Typical symptoms include: nausea, vomiting, headache, abdominal cramps, breathing difficulty, abnormal body temperature, pallor, diarrhea, chills, fluctuations in blood pressure and heart rate, drenching sweats and increased salivation. ${ }^{1-3}$ Green tobacco sickness has not yet been reported in Poland.

A 25-year-old-man, with pesticide poisoning symptoms (as an initial diagnosis) was admitted to the Department of Clinical Toxicology, Jagiellonian University Medical College. The man had been working on a tobacco plantation for 14 hours. He was breaking the tops of the Virginia bright tobacco stalks to improve plant growth; he performed the procedure with bare hands. On the day of exposure the weather was sunny; the temperature was about $26^{\circ} \mathrm{C}$. During the first 3 hours of work he wore a short-sleeved T-shirt, which he subsequently took off. The man was sweaty and did not use any protective measures (gloves, a mask, clothing), or decontamination methods. In the evening, having finished work he merely washed his face, hands, and forearms up to the elbows. The symptoms occurred about 3 hours after work completion. They involved diplopia, vomiting, diarrhea, dizziness, fatigue, drenching sweats, and flushing of the face. The examination performed on admission showed tachycardia $124 / \mathrm{min}$ and horizontal nystagmus diplopia had already subsided. During the neurological consultation a dorsal position of the hallux and neck stiffness were found. The neurological symptoms persisted for about 2 hours. Examinations showed normal blood pressure values. The toxicological examination excluded herbicide and pesticide poisoning with acetylcholinesterase (AChE) inhibitors, phenoxyacetic acid and aniline derivatives. Toxicological 
analysis of urine showed a cotinine level of 869 $\mathrm{ng} / \mathrm{ml}$, which significantly exceeded the levels found in nonsmokers. The man had never been a cigarette smoker, nor was he exposed to passive smoking. Intravenous fluids and anticholinergic agents were administered. Given potassium deficiency, a blood level of $3.21 \mathrm{mmol} / \mathrm{l}$, kalium supplementation was administered. The symptoms of GTS subsided on the 3rd day of hospital stay. The urine cotinine level measured on the 3rd day was $61 \mathrm{ng} / \mathrm{ml}$. The Holter monitoring and the abdominal ultrasonography were normal. The patient was followed-up for another 4 days, and laboratory check-up tests performed during that time did not show any abnormalities. The patient was discharged home on the 7th day in a good condition.

DISCUSSION Nicotine is a liquid alkaloid found in tobacco. Administered to laboratory animals it stimulates the vagus nerve ganglia, reducing heart rate and lowering blood pressure. It subsequently stimulates the catecholamine adrenal release, thus increasing transiently blood pressure. In higher doses nicotine inhibits the ganglia, thus lowering the arterial blood pressure. ${ }^{4}$ Green tobacco sickness is not a direct life-threatening condition, or it does not cause long-term outcomes. The symptoms of GTS usually resolve spontaneously within 23 days. However, the disease results in discomfort among tabacco workers. The weather is an important factor affecting the risk of GTS. Rainy and humid days especially increase the nicotine dermal absorption inducing a higher morbidity rate. The use of protective clothing, raincoats, gloves, and rubber boots decrease the transdermal absorption of nicotine. ${ }^{3}$ Washing hands with water and soap (or another detergent) removes even up to $96 \%$ of nicotine from hands of people working on tobacco plantations. ${ }^{3}$ The total area of tobacco plantations in Poland is about 14,000 hectares (34,594 acres); the crops are nearly 30,000 tons a year. Tobacco requires laborious procedures, during which the leaf quality is being improved. For this reason the lateral burgeons and inflorescences are being removed. The leaves are being harvested in a dry and sunny weather. The work involves tobacco hand-growing and hand-harvesting. Toxicology centers report numerous pesticide poisonings among agricultural workers each year; however GTS has not been reported in Poland yet. The symptoms observed in the current case were typical of GTS, moreover diplopia and nystagmus were noted. It was suggested that diplopia had been nicotine induced. Acetylcholine (ACh), affecting mainly the $\mathrm{N}$ receptor, is the transmitter in the ganglia of the autonomous (sympathetic and parasympathetic) nervous system. Numerous chemical compounds affect the ganglia of the autonomous nervous system similarly to ACh. ${ }^{5}$ These compounds include nicotine and lobeline. Unlike ACh, they are not decomposed by AChE. The depolarization process is therefore prolonged. In consequence their effect is biphasic: at first they stimulate the ganglia, and then inhibit the conduction of stimuli. In the current patient diplopia was most probably associated with stimulation inhibition. ${ }^{4}$ In available data on GTS no such neurological disorders have been reported yet. The patient had similar, typical of GTS symptoms without neurological disorders several days earlier while he was working on the tobacco plantation. They were however less intense and resolved spontaneously within 12 hours, which is why the patient did not seek medical aid. This is the first case of GTS reported in Poland. There is however a high likelihood of occurrence of this disease.

Tobacco workers perform numerous activities manually with no use of protective clothes. They do not use skin decontamination methods either. Moreover, the use of herbicide may confuse GTS with herbicide poisoning. Furthermore, if symptoms resolve spontaneously, subjects do not report to the doctor. It seems vital to launch a campaign on the use of protective measures and decontamination rules during work in tobacco farming.

\section{REFERENCES}

1 McKnight RH, Spiller HA. Green tobacco sickness in children and adolescents. Public Health Rep. 2005; 120: 602-606.

2 McBride JS, Altman DG, Klein M, White W. Green tobacco sickness. Tob Control. 1998; 7: 294-298.

3 Curwin BD, Hein MJ, Sanderson WT, et al. Nicotine exposure and decontamination on tobacco harvesters' hands. Ann Occup Hyg. 2005; 49: 407-413.

4 Dawson RF, Solt ML. Nicotine and its botanical sources. Ann NY Acad Sci. 1960; 90: 7-11.

5 Rucker JC. Oculomotor disorders. Semin Neurol. 2007; 27: 244-256. 